\title{
Factors study influencing on numerical simulation of aircraft windshield against bird strike
}

\author{
F.S. Wang*, Z.F. Yue and W.Z. Yan \\ School of Mechanics, Civil Engineering and Architecture, Northwestern Polytechnical University, Xi'an, P.R. China
}

Received 8 November 2009

\begin{abstract}
The combined model of UniGraphics(UG) and ANSYS-LS-DYNA software and finite element (FE) model of aircraft windshield and windshield structure for bird strike were built. The windshield structure is composed of windshield, framework, arc-frame and gasket. The factors influencing on dynamic response for bird strike were analyzed such as bird velocity, mesh density of windshield, mesh density of bird, boundary condition, material model of windshield, analytic methods and components of windshield structure. The results showed that these factors must be taken into account when FE analysis method is applied to aircraft anti-bird design.
\end{abstract}

Keywords: Bird strike, aircraft windshield, numerical simulation, contact-impact coupling algorithm, dynamic response

\section{Introduction}

Aircraft anti-bird design starts from bird strike test including air cannon and rocket sled testing methods. Air cannon method is generally used for bird strike test [1]. The bird strike test is effective in checking anti-bird capacity of specimen, determining aircraft critical velocity as well as measuring the datum such as displacement, strain responses and strike force to provide for design and production selection. However, bird strike test is blind and can not instruct aircraft design beforehand. Fortunately, FE numerical analysis method for bird strike can cover the shortage of bird strike test not only in saving the cost of test but also in guaranteeing to finish the aircraft design on schedule. So, it is of great importance to deeply develop FE numerical analysis technique for anti-bird strike design of aircraft structures.

Uncoupling and coupling solutions have been widely used in FE numerical simulation of bird strike problems [2]. The former considers only the dynamic response and material failure of structure, and it generally doesn't build up the FE model of bird. Instead, it simulates the temporal and spatial variation of bird strike loading with several hypotheses. Then the loading is acted on the structure and the response is calculated independently. Although this solution can reduce the calculation difficulty and expenses as well as avoid the complexity of impact question, it needs modeling a bird strike loading beforehand which will significantly affect the numerical simulation results of structure. In fact, all the bird strike loading models available in literatures always ignore some factors more or less and result in a coarse solution [3-5]. In contrast, the latter can combine the structure model with bird model. The two models are connected through compatibility condition on the contact interface. The dynamic responses of structure and bird in addition to the contact force between them can be obtained based on a set of equations which satisfies the compatibility condition. This solution can simulate the whole progress of bird strike and be accepted as an ideal

*Corresponding author. Tel.: +8629 88431002; Fax: +86 29 88431002; E-mail: wangfs620@163.com. 


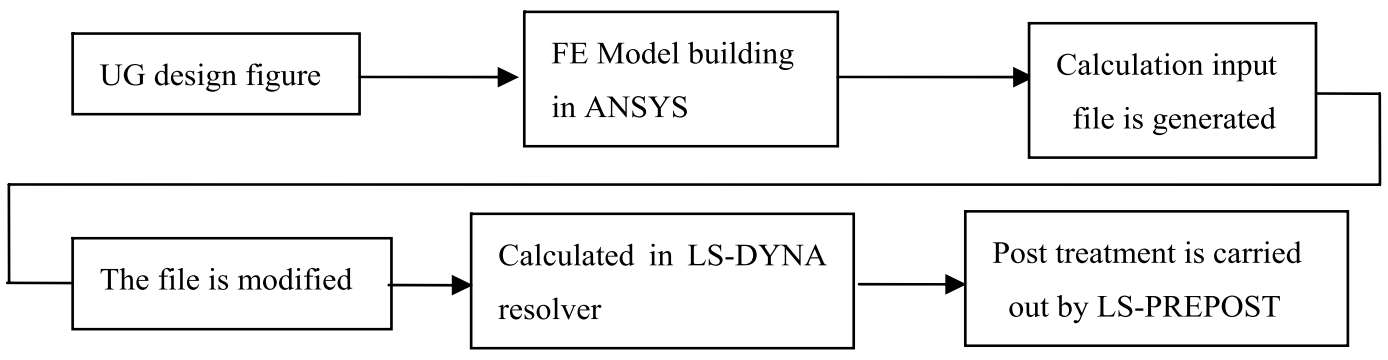

Fig. 1. The building process about combined model of UG and ANSYS-LS-DYNA.

approach at present, such as contact-impact coupling algorithm [6,7] and fluid-structure coupling algorithm [8]. Recently, SPH method is also applied to the anti-bird study of aircraft structure in order to fit for the strike question with much bigger bird velocity [9-11]. There doesn't appear mesh distortion and thus it can deal with the larger deformation under Lagrangian technique. Based on the contact-impact coupling algorithm, factors influencing on FE numerical simulation of aircraft windshield for bird strike will be analyzed in the present study.

\section{The combined model of UniGraphics (UG) and ANSYS-LS-DYNA software}

\subsection{The building process of the combined model}

Two types of software will be used. One is UniGraphics [12], in which the geometry models will be built. The other is the FE analysis software ANSYS [13], in which LS-DYNA module is contained and called ANSYS-LSDYNA. LS-DYNA is used for explicit dynamic calculation of structure, for example impact and explosion problem. Here, the pre-treatment program and post treatment program are ANSYS and LS-PREPOST, respectively.

Aircraft windshield structure is composed of windshield, framework, arc-frame and gasket. The gasket is located between windshield and framework and between windshield and arc-frame. The geometry models of windshield, framework and arc-frame are built in UG software. Although LS-DYNA has a powerful dynamic analytic capacity, its preprocessor has no interface with UG software. So, the combined model building of UG and ANSYS-LS-DYNA is developed, which has some similar aspects with the combined model of CATIA and ANSYS-LS-DYNA in Ref. [1]. Here, the function of CATIA software is the same as UG. The detailed technique process is given as following.

Step I: UG models are import into ANSYS software. Because there has no the UG figure of gasket, its geometry model is generated in ANSYS by the outline of windshield, framework and arc-frame.

Step II: The FE models of aircraft windshield and windshield structure are built in ANSYS software.

Step III: The calculation input file is generated. The part controlled keywords are modified, added and deleted in the file and then submitted to calculate in LS-DYNA resolver.

Step IV: When the calculation ends up, the post treatment program LS-PREPOST in LS-DYNA will be used to deal with the results.

The building process about combined model of UG and ANSYS-LS-DYNA is shown in Fig. 1.

\subsection{The methods importing UG design figure into ANSYS software}

Three main methods importing UG designed figure into ANSYS software are given as follows.

Method I: UG designed figure is imported into ANSYS directly. This method needs a special dynamic chained library to support. When ANSYS software is installed, the corresponding installation file needs to specifying.

Method II: The geometry models are partitioned according to the cross section in UG software. All key points are extracted and input into ANSYS software. Then the B spline curve of cross section is rebuilt and each curve is smoothed in order to make curved face of windshield become integrity. 


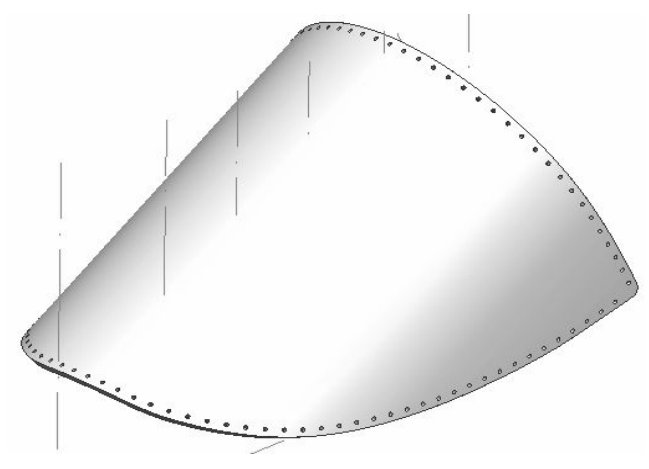

Fig. 2. The windshield in UG software.

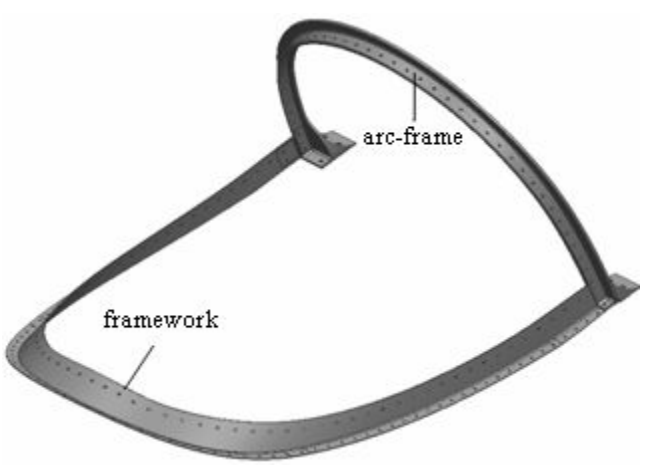

Fig. 3. The framework and arc-frame in UG software.

Method III: UG designed figure is output into the corresponding text file by the parasolid or IGES format and then this file is imported into ANSYS software.

Method III has a good adaptability and is simple and reliable. Here, designed figures of aircraft windshield, framework and arc-frame are imported into ANSYS software by just this method. The designed figures of aircraft windshield, framework and arc-frame in UG software are shown in Figs 2 and 3, respectively.

\section{The FE models of windshield and windshield structure}

\subsection{Material models $[14,15]$}

The geometry model of bird body used for numerical simulation is a cylinder. When the bird weighs $1.8 \mathrm{~kg}$ according to army test standard, the diameter and length of cylinder are selected as $140 \mathrm{~mm}$ and $280 \mathrm{~mm}$, respectively. The real bird body is such a mixture of skeleton, blood as well as muscle that it's difficult to describe its constitutive model. So far, the simulation of quasi-real bird body has never been reported. Here, Plastic Kinematic model is chosen as the bird constitutive model [1]. Windshield material is MDYB-3 oriented Polymethyl Methacrylate(PMMA) and simulated as elastic model or Plastic Kinematic model. Framework and arc-frame material is LD5 wrought Aluminium alloy and simulated as elastic model. Gasket material is simulated as elastic model too. Material parameters of each model are listed in Table 1.

For the elastic material model, the co-rotational rate of deviatoric Cauchy stress tensor is computed as

$$
s_{i j}^{\nabla^{n+1 / 2}}=2 G \dot{\varepsilon}_{i j}^{\prime n+1 / 2}
$$

and pressure is computed as 
Table 1

Material parameters

\begin{tabular}{lcccccc}
\hline Model & $\begin{array}{c}\text { Density } \\
\left(\mathrm{kg} / \mathrm{m}^{3}\right)\end{array}$ & $\begin{array}{c}\text { Young's modulus } \\
(\mathrm{GPa})\end{array}$ & $\begin{array}{c}\text { Poisson 's } \\
\text { ratio }\end{array}$ & $\begin{array}{c}\text { Yield stress } \\
(\mathrm{MPa})\end{array}$ & $\begin{array}{c}\text { Tangent modulus } \\
(\mathrm{MPa})\end{array}$ & $\begin{array}{c}\text { Failure } \\
\text { strain }\end{array}$ \\
\hline bird & 900 & 10.0 & 0.3 & 1.0 & 5.0 & 1.25 \\
windshield & 1190 & 3.13 & 0.426 & 68 & 0.067 \\
framework and arc-frame & 2750 & 71 & 0.3 & & \\
gasket & 1040 & 30 & 0.3 & & \\
\hline
\end{tabular}

$$
p^{n+1}=-K \ln V^{n+1}
$$

Where $G$ and $K$ are the elastic shear and bulk moduli, respectively. $V$ is the relative volume, i.e., the ratio of the current volume to the initial volume.

For the Plastic Kinematic material model, the yield condition is expressed as

$$
\phi=\sigma_{i}^{2}-\sigma_{y}^{2}=0
$$

Where the stress strength is expressed as

$$
\sigma_{i}=\sqrt{\frac{3}{2}\left(s_{i j}-\alpha_{i j}\right)\left(s_{i j}-\alpha_{i j}\right)}
$$

The deviatoric stress is expressed as

$$
s_{i j}=\sigma_{i j}-\frac{1}{3 \sigma_{k k}}
$$

The increment of translation tensor $\alpha_{i j}$ is expressed as

$$
\Delta \alpha_{i j}=(1-\beta) \frac{2}{3} E_{p} \dot{\varepsilon}_{i j}^{p} \Delta t
$$

Here, $\beta$ is the hardening parameter. For $\beta$ equal to 0 and 1, respectively, kinematic and isotropic hardenings are obtained.

The plastic hardening modulus is expressed as

$$
E_{p}=\frac{E E_{T}}{E-E_{T}}
$$

The current yield stress is expressed as

$$
\sigma_{y}=\sigma_{0}+\beta E_{p} \varepsilon_{e f f}^{p}
$$

Here, $\sigma_{0}$ is the initial yield strength.

The effective plastic strain is expressed as

$$
\varepsilon_{e f f}^{p}=\int_{0}^{t}\left(\frac{2}{3} \dot{\varepsilon}_{i j}^{p} \dot{\varepsilon}_{i j}^{p}\right)^{\frac{1}{2}} d t
$$

The plastic strain rate is the difference between the total and the elastic strain rate and expressed as

$$
\dot{\varepsilon}_{i j}^{p}=\dot{\varepsilon}_{i j}-\dot{\varepsilon}_{i j}^{e}
$$

\subsection{The FE models}

In order to simplify analysis, all rivets in Figs 2 and 3 are deleted and the lower arc-frame is improved. The FE model of windshield is shown in Fig. 4. The FE model of framework and arc-frame is shown in Fig. 5. The FE model of gasket is shown in Fig. 6. The element types of bird, windshield, framework, arc-frame and gasket are all chosen as eight-node solid isoparametric element.

FE models of windshield and windshield structure for bird strike are shown in Figs 7 and 8, respectively. Longitudinal axes of the bird passes the center of camber line on outer surface of windshield horizontally. 


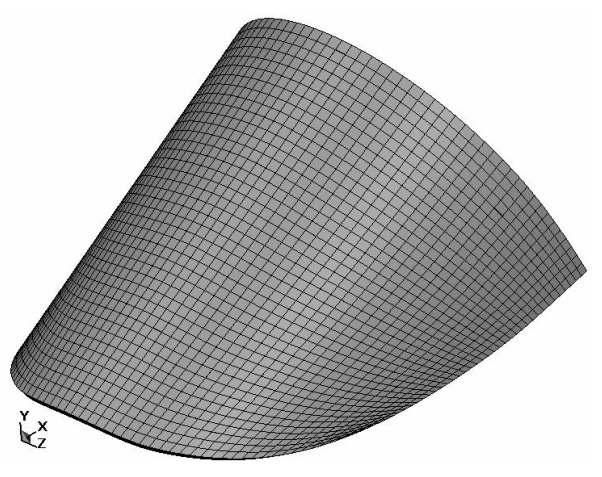

Fig. 4. FE model of windshield.

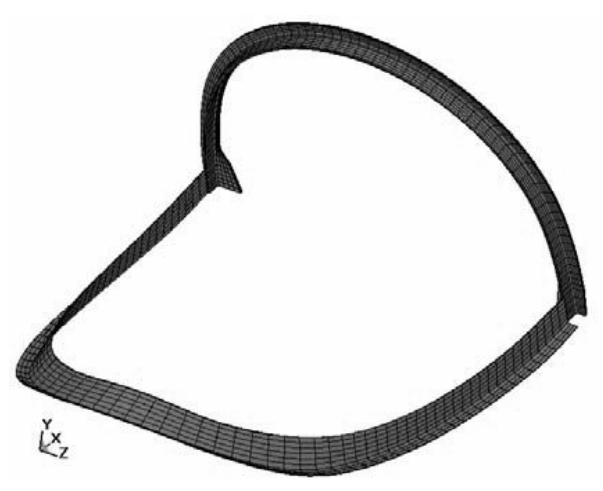

Fig. 5. FE model of framework and arc-frame.

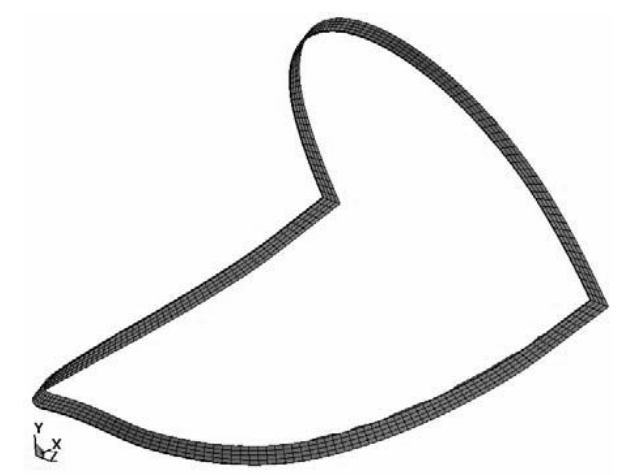

Fig. 6. FE model of gasket.

\subsection{Boundary conditions}

For FE model of windshield, all edges are fixed. For FE model of windshield structure, those parts connected with airplane are fixed.

\subsection{Contact relationship [16]}

Nodes-surface contact form is applied between bird and windshield. Surface-surface tied contact form is applied between windshield and gasket, framework and gasket as well as arc-frame and gasket. Since element type is chosen 


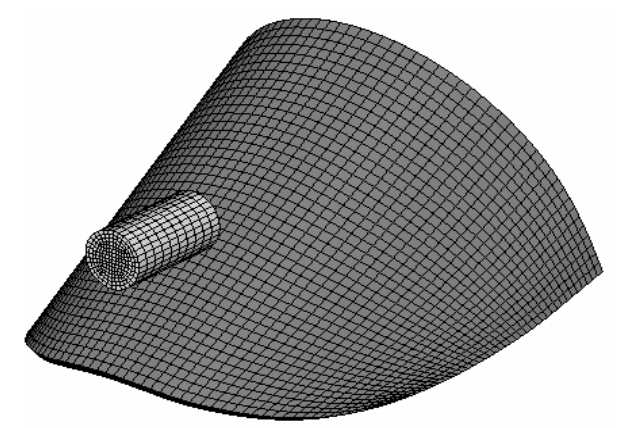

Fig. 7. FE model of windshield for bird strike.

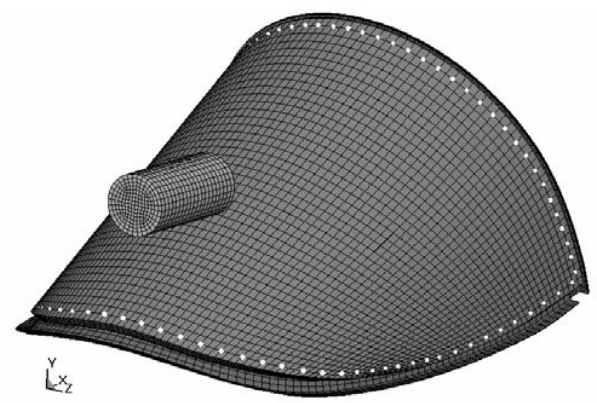

Fig. 8. FE model of windshield structure for bird strike.

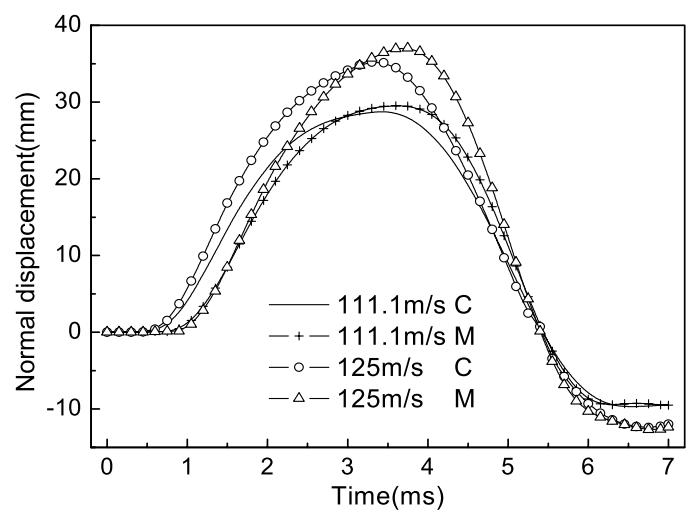

(C: the center; M: point of maximal normal displacement)

Fig. 9. Time history of normal displacement at the center and point of maximal normal displacement on inner surface.

as eight-node solid isoparametric element, nodes-nodes rivet form is applied. All the contact form can be defined by keywords.

\section{Factors influencing on numerical simulation of windshield for bird strike}

\subsection{Bird velocity}

When the bird velocity is selected as $125 \mathrm{~m} / \mathrm{s}$ (or $450 \mathrm{~km} / \mathrm{h}$ ) and $111 \mathrm{~m} / \mathrm{s}$ (or $400 \mathrm{~km} / \mathrm{h}$ ), time histories of normal displacement at the center and point of the maximal normal displacement on inner surface are shown in Fig. 9. For 
Table 2

The maximal normal displacement on inner surface (unit: $\mathrm{mm}$ )

\begin{tabular}{ccc}
\hline Velocity $(\mathrm{m} / \mathrm{s})$ & The center & Point of the maximal normal displacement \\
\hline 111.1 & 29.56 & 30.55 \\
125 & 36.20 & 38.29 \\
\hline
\end{tabular}

Table 3

The maximal normal displacement at the center on inner surface for different mesh seeds along thickness of windshield (unit: $\mathrm{mm}$ )

\begin{tabular}{ccccc}
\hline Velocity $(\mathrm{m} / \mathrm{s})$ & Three points & Five points & Six points & Nine points \\
\hline 111.1 & 31.84 & 29.87 & 29.56 & 29.20 \\
125 & 38.57 & 36.53 & 36.20 & 35.77 \\
\hline
\end{tabular}

Table 4

The maximal normal displacement at the center on outer surface for different mesh seeds along thickness of windshield (unit: $\mathrm{mm}$ )

\begin{tabular}{ccccc}
\hline Velocity $(\mathrm{m} / \mathrm{s})$ & Three points & Five points & Six points & Nine points \\
\hline 111.1 & 33.25 & 30.91 & 30.55 & 30.10 \\
125 & 41.54 & 38.71 & 38.29 & 37.75 \\
\hline
\end{tabular}

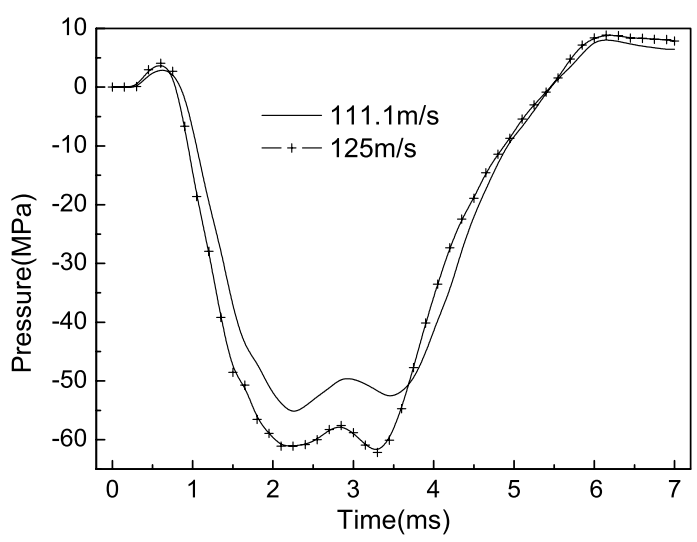

Fig. 10. Time history of pressure at the center on inner surface.

each node on inner surface of windshield, the time history of normal displacement can be shown and the maximal normal displacement will occur during the impact interval. Point of the maximal normal displacement refers to the node that maximal normal displacement value is largest in all nodes on inner surface of windshield. The maximal normal displacements of two points are given in Table 2. It can be seen that when bird velocity is larger, maximal normal displacements of two points are greater and need a longer time to reach. For each point, the time to reach the maximal normal displacement is the same for both of the two velocities. For both of the two points, the time to reach maximal normal displacement is $3.3 \mathrm{~ms}$ and $3.45 \mathrm{~ms}$, respectively.

For the two velocities, time history of pressure at the center on inner surface is shown in Fig. 10. It can be seen that the pressures have the same trend for the two velocities. When bird velocity is equal to $125 \mathrm{~m} / \mathrm{s}$, the maximal absolute value of pressure is equal to $62.17 \mathrm{MPa}$. When bird velocity is equal to $111 \mathrm{~m} / \mathrm{s}$, the maximal absolute value of pressure is equal to $52.87 \mathrm{MPa}$. The time to reach the maximal absolute value of pressure decreases with the increase of bird velocity.

\subsection{Mesh density of windshield}

Time history of normal displacement at the center on inner surface for both of the two velocities is shown in Fig. 11 when the quantity of mesh seeds along thickness of windshield is 3,5,6 and 9, respectively. The maximal normal 
Table 5

The maximal normal displacement at the center on inner surface for different mesh seeds along camber line of windshield (unit: $\mathrm{mm})$

\begin{tabular}{cccc}
\hline Velocity $(\mathrm{m} / \mathrm{s})$ & forty points & Sixty points & Eighty points \\
\hline 111.1 & 29.87 & 30.00 & 30.05 \\
125 & 36.53 & 36.70 & 36.74 \\
\hline
\end{tabular}
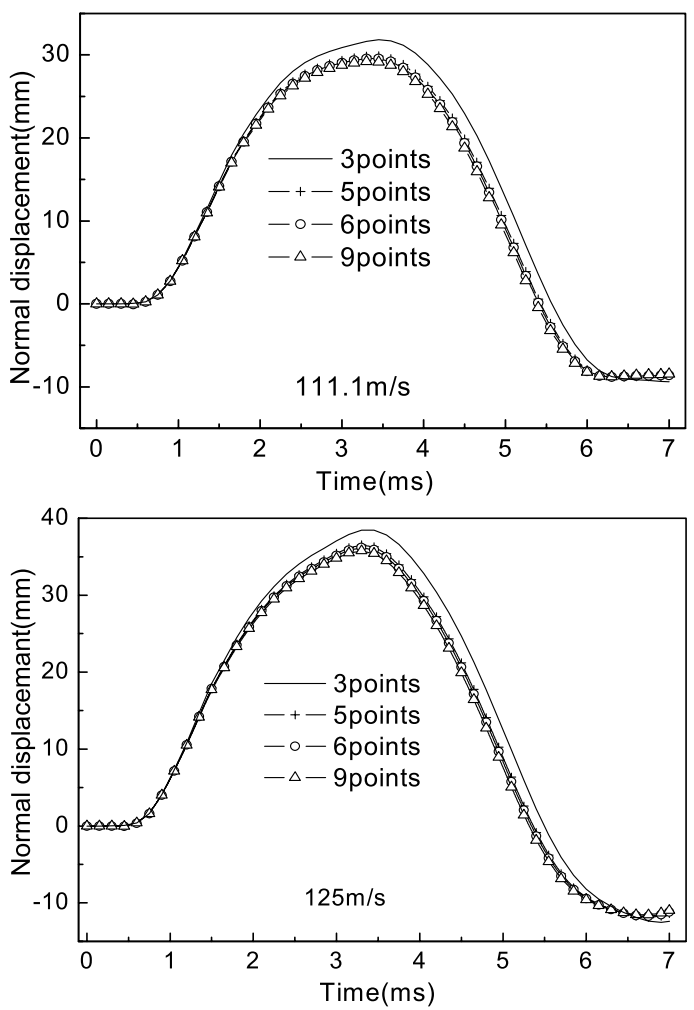

Fig. 11. Time history of normal displacement at the center on inner surface for different mesh seeds along thickness of windshield.

displacements at the center on inner surface and that on outer surface are given in Tables 3 and 4, respectively. It can be seen that when the quantity of mesh seeds along thickness becomes less, the calculation results vary dramatically. When quantity of mesh seeds along thickness is larger, it has little influence on calculation results but increases the calculation time. For example, it will take about 16 minutes to complete the calculation when quantity of mesh seeds along thickness is equal to 3 while it will take about 32 minutes to complete the calculation when quantity of mesh seeds along thickness is equal to 9. So, a compromise should be achieved between the calculation time and precision.

Time history of normal displacement at the center on inner surface for both of the two velocities is shown in Fig. 12 when quantity of mesh seeds along camber line of windshield is 40, 60 and 80, respectively. The maximal normal displacement is given in Table 5. Time history of pressure at the center on outer surface for the two velocities is shown in Fig. 13 for three above mentioned mesh seeds. It can be seen that quantity of mesh seeds along camber line of windshield has little influence on the calculation results.

\subsection{Mesh density of bird}

Time history of normal displacement at the center on inner surface of windshield for the two velocities is shown in Fig. 14 when the quantity of mesh seeds along central axis of bird is 10, 20 and 30, respectively. The maximal 
Table 6

The maximal normal displacement at the center on inner surface for different mesh seeds along central axis of bird (unit: $\mathrm{mm}$ )

\begin{tabular}{cccc}
\hline Velocity $(\mathrm{m} / \mathrm{s})$ & Ten points & Twenty points & Thirty points \\
\hline 111.1 & 29.69 & 30.04 & 30.00 \\
125 & 36.66 & 36.55 & 36.17 \\
\hline
\end{tabular}
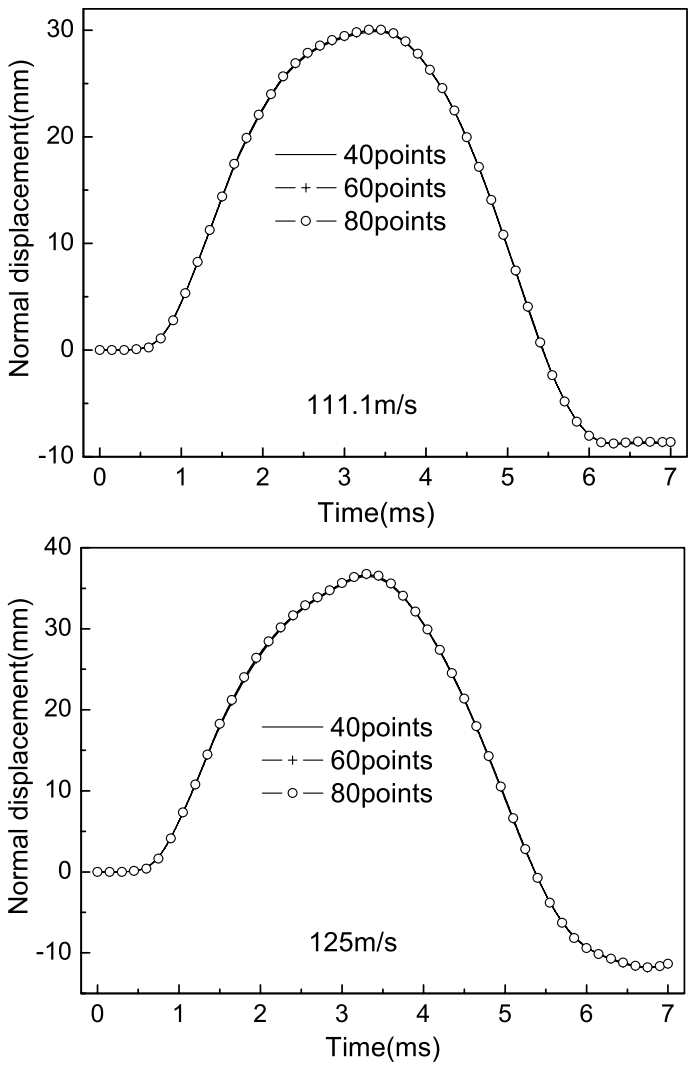

Fig. 12. Time history of normal displacement at the center on inner surface for different mesh seeds along camber line of windshield.

normal displacement at the center on inner surface is given in Table 6. It can be seen that mesh seeds along central axis of bird influences little on the maximal normal displacement at the center on inner surface.

\subsection{Boundary condition}

Time history of normal displacement at the center on inner surface of windshield for the two velocities is shown in Fig. 15 under the boundary condition of no constraint, xy constraint and all constraint. Time history of pressure at the center on inner surface for the two velocities is shown in Fig. 16 at the same conditions. It can be seen that boundary condition has little influence on normal displacement and pressure at the center on inner surface in initial time. Subsequently, when boundary condition is stronger, normal displacement at the center on inner surface is smaller while the maximal absolute value of pressure at this point is larger. When no constraint is selected as the boundary condition, windshield will occur to translational motion. Additionally, normal displacement at the center on inner surface continues to increase and the absolute value of pressure at this point decreases gradually.

\subsection{Material model of windshield}

Time history of normal displacement at the center on inner surface of windshield is showed in Fig. 17 when mat- 

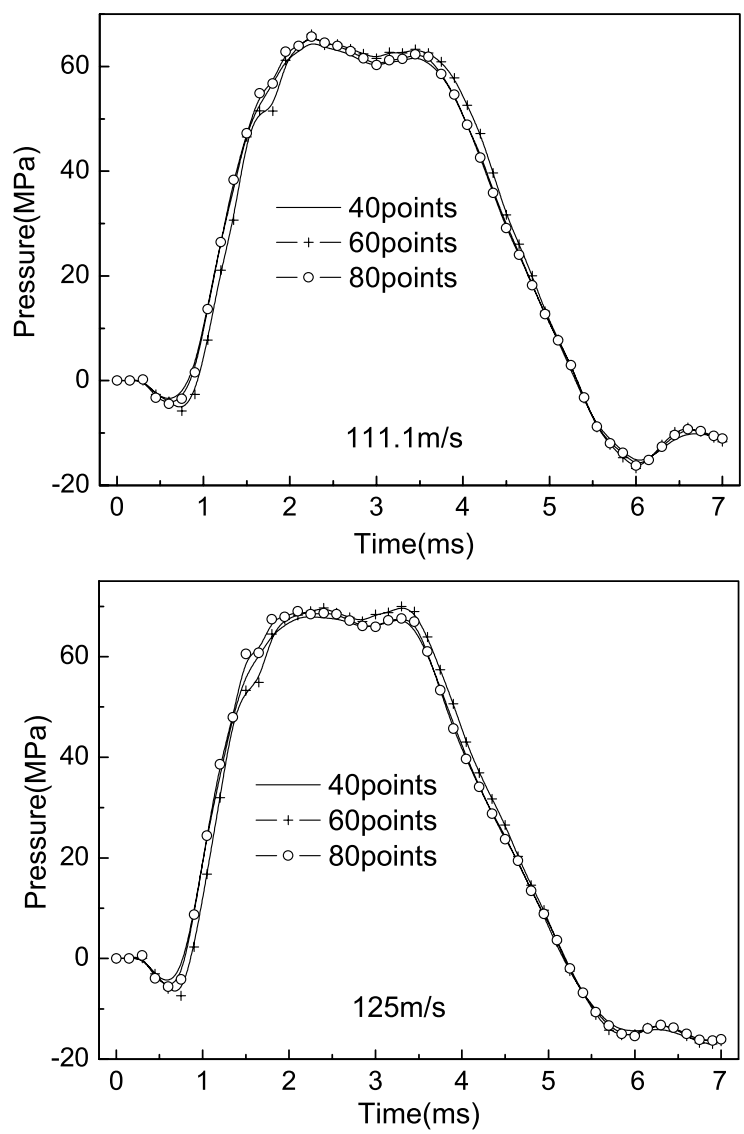

Fig. 13. Time history of pressure at the center on outer surface for different mesh seeds along camber line of windshield.

erial models of windshield are plastic Kinematic model and elastic material model, respectively. It can be seen that normal displacement at the center on inner surface is almost the same in initial time under the two conditions. Subsequently, when plastic Kinematic model is selected as the material model of windshield, normal displacement at this point is lager than that of elastic material model.

Time history of strain at the center on inner surface of windshield along $\mathrm{x}$, y and xy direction is shown in Fig. 18 for both of the two material models. Time history of pressure at the center on inner and outer surface is shown in Fig. 19. It can be seen that when plastic Kinematic model is selected as material model of windshield, the absolute value of strain at this point along $\mathrm{x}, \mathrm{y}$ and $\mathrm{xy}$ direction is lager than that of elastic material model. The absolute values of pressure at the center on inner surface and outer surface of windshield are smaller than those of elastic material model.

\subsection{Analytic methods}

When bird velocity is $125 \mathrm{~m} / \mathrm{s}$, time histories of normal displacement and pressure at the center on inner surface of windshield are shown in Figs 20 and 21 by simulating bird as Lagrange and ALE elements, respectively. It can be seen that calculation results is almost the same for the two methods. So, when bird velocity is equal to or less than $125 \mathrm{~m} / \mathrm{s}$, it's reasonable to simulate bird as Lagrange element.

\subsection{The components of windshield structure}

For the FE models of windshield and windshield structure for bird strike, time histories of kinetic energy and total energy of windshield are shown in Figs 22 and 23, respectively. Time history of total energy of bird is shown in 

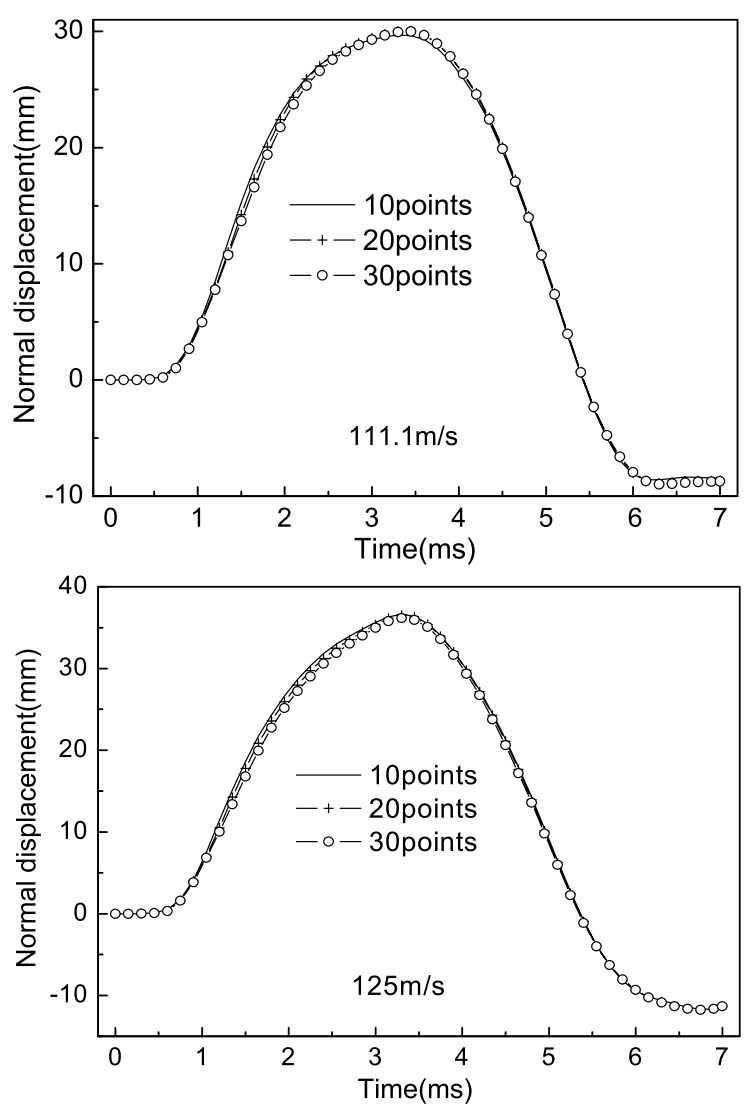

Fig. 14. Time history of normal displacement at the center on inner surface for different mesh seeds along central axis of bird.

Fig. 24. It can be seen that framework, arc-frame and gasket influence greatly on kinetic energy and total energy of windshield but little on total energy of bird. The maximal kinetic energy by model of windshield will arrive earlier than that by model of windshield structure. The maximal kinetic energy is almost the same under the two conditions. The total energy of windshield by model of windshield decreases gradually after some time while that by model of windshield structure varies greatly due to the energy exchanges between windshield and gasket, gasket and framework as well as gasket and arc-frame.

Under the two conditions, time history of normal displacement at the center on inner surface of windshield is shown in Fig. 25. It can be seen that framework, arc-frame and gasket influence greatly on normal displacement at the center on inner surface of windshield structure. The maximal normal displacement by model of windshield structure arrives later and is larger than that by model of windshield.

Under the two conditions, time histories of pressure at initial strike point, at the center on outer surface and at vertex of camber line on outer surface of windshield are shown in Figs 26, 27 and 28, respectively. It can be seen that the maximal pressures at initial strike point and the center on outer surface are almost the same under the two conditions. While the maximal pressure at vertex of camber line on outer surface by model of windshield structure is larger than that by model of windshield. For each point, variation of pressure by model of windshield is greater than that by model of windshield structure.

\section{Conclusions}

The following conclusions can be drawn through factors study influencing on numerical simulation of windshield for bird strike. 

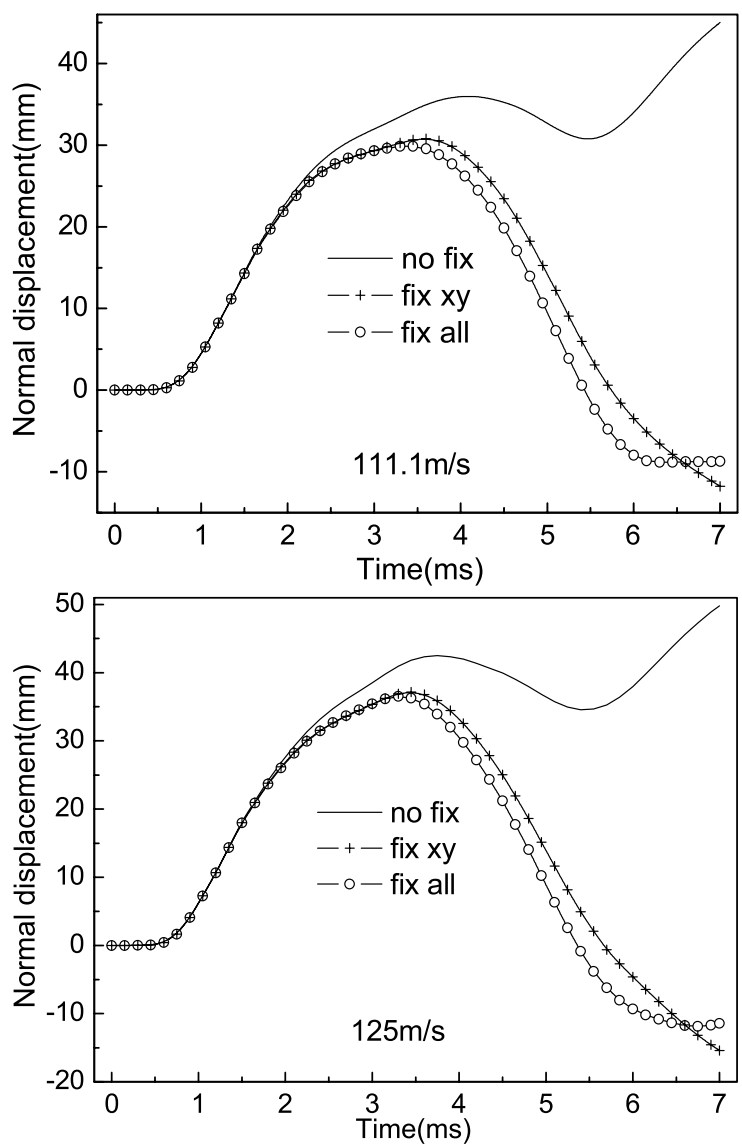

Fig. 15. Time history of normal displacement at the center on inner surface for different boundary conditions.

(1) When bird velocity is larger, the maximal normal displacements at the center on inner surface and point of the maximal normal displacement are greater and need a longer time to reach. Pressure at the center on inner surface has the same trend for different bird velocities. When bird velocity is larger, the time to reach the maximal absolute value of pressure is shorter.

(2) When quantity of mesh seeds along thickness of windshield is less, it influences greatly on calculation results. While quantity of mesh seeds along thickness is larger, it influences little on calculation results. A compromise should be achieved between the calculation time and the calculation precision. Quantity of mesh seeds along camber line of windshield and that along central axis of bird influence little on calculation results.

(3) In initial strike, boundary condition has little influence on normal displacement and pressure at the center on inner surface. Subsequently, when boundary condition is stronger, normal displacement at the center on inner surface is smaller and the maximal absolute value of pressure at this point is larger. When no constraint is selected as boundary condition, windshield will occur to translational motion. Additionally, normal displacement at the center on inner surface continues to increase while the absolute value of pressure at this point decreases gradually.

(4) When plastic Kinematic model and elastic material model are selected as the material models of windshield, normal displacements at the center on inner surface are almost the same under the two conditions in initial strike. Subsequently, when plastic Kinematic model is selected, normal displacement at this point and the absolute value of strain at the center on inner surface of windshield along $x, y$ and xy direction are lager than those of elastic material model. While the absolute value of pressures at the center on inner surface and outer surface of windshield are smaller than those of elastic material model. 

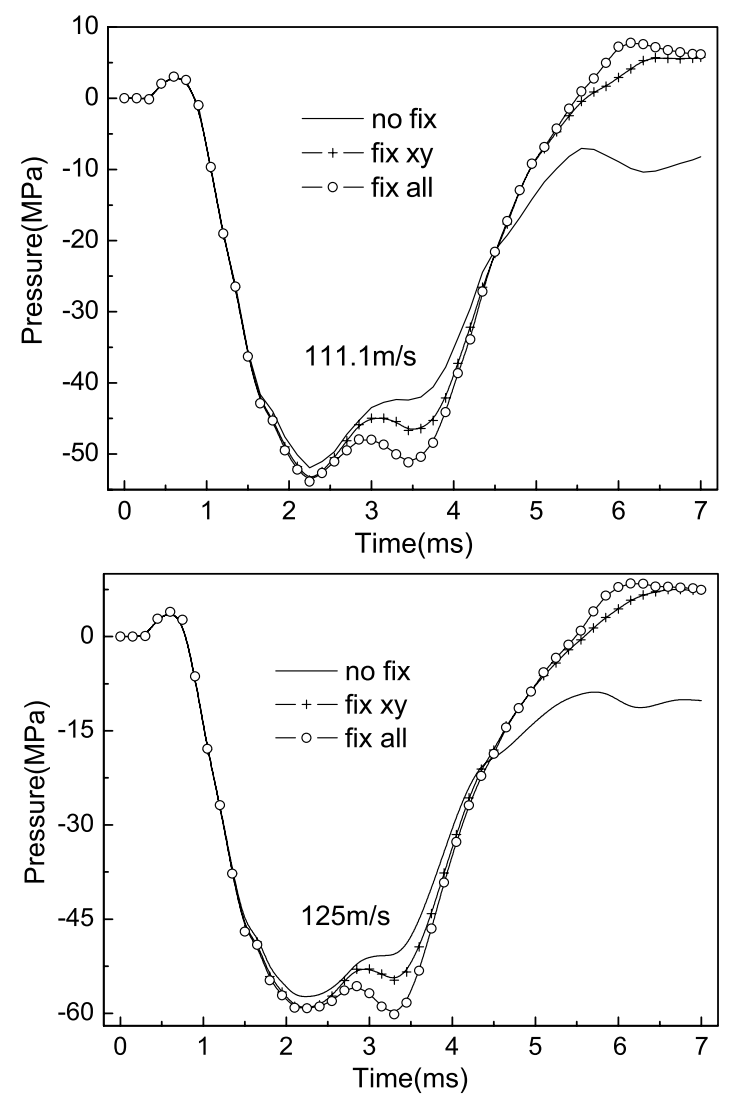

Fig. 16. Time history of pressure at the center on inner surface for different boundary conditions.

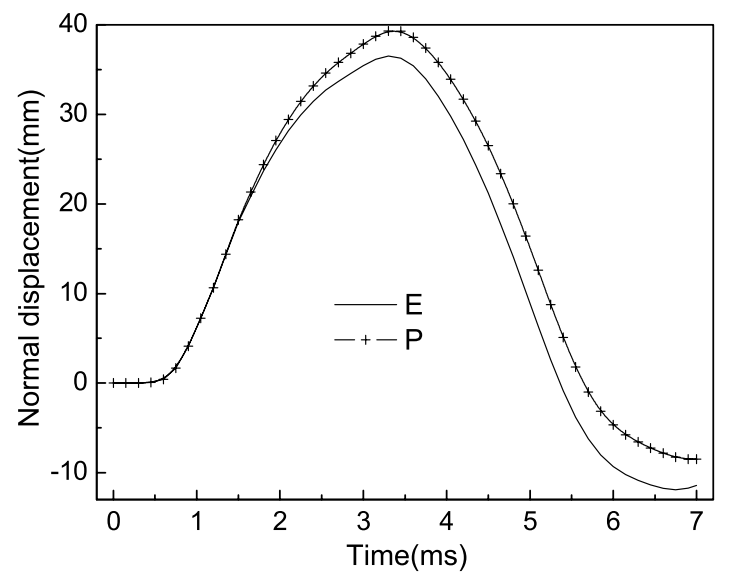

Fig. 17. Time history of normal displacement at the center on inner surface for different material models of windshield.

(5) When bird velocity is relatively less, calculation results are almost the same by simulating bird as Lagrange and ALE elements, respectively.

(6) Framework, arc-frame and gasket influence greatly on kinetic energy and total energy of windshield but little on total energy of bird. The maximal kinetic energy by model of windshield will arrive earlier than that by model of windshield structure. The maximal kinetic energy is almost the same under the two conditions. The 


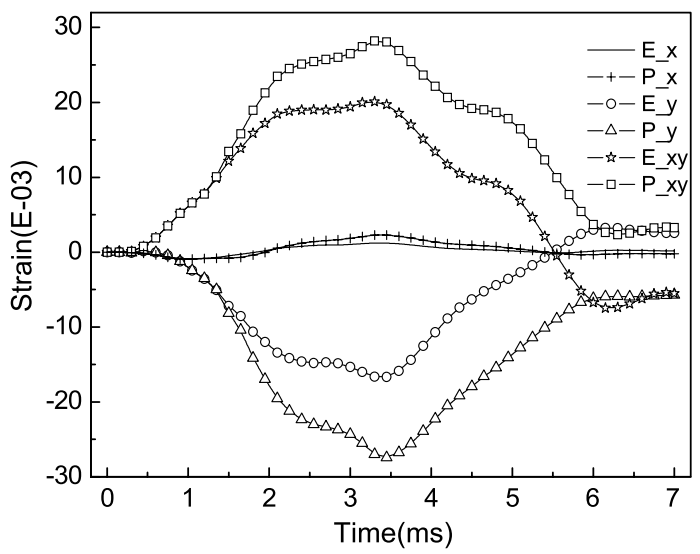

Fig. 18. Time history of strain at the center on inner surface for different material models of windshield.

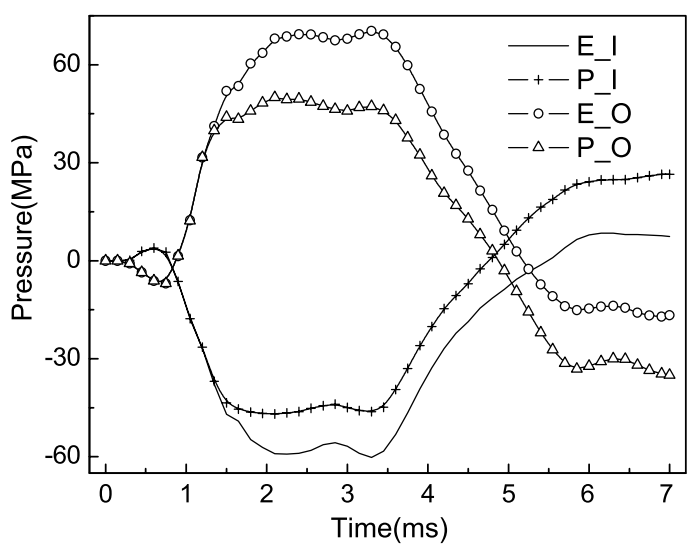

(I: inner surface; O: outer surface)

Fig. 19. Time histories of pressure at the center on inner surface and outer surface for different material models of windshield.

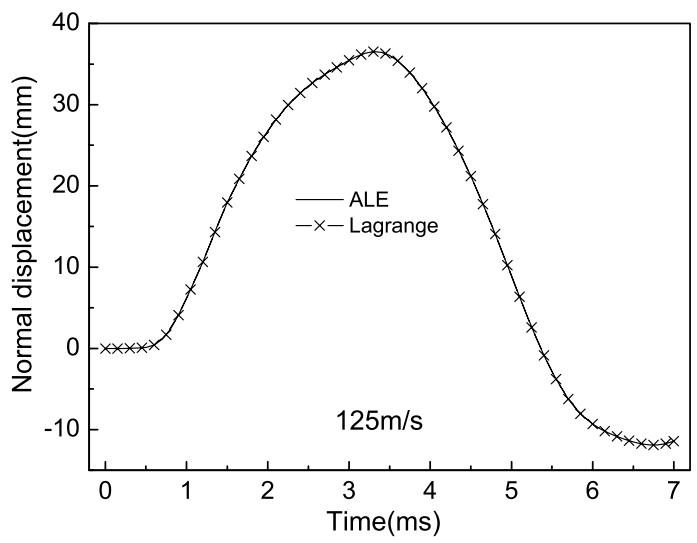

Fig. 20. Time history of normal displacement at the center on inner surface of windshield for different analytic methods. 


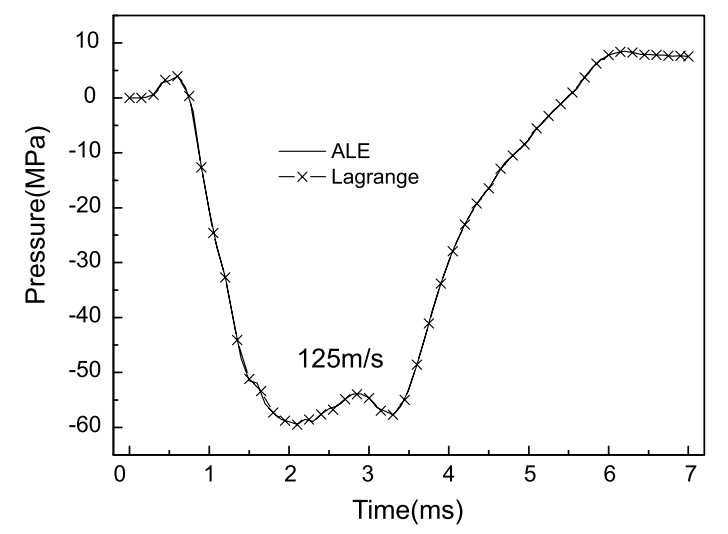

Fig. 21. Time history of pressure at the center on inner surface of windshield for different analytic methods.

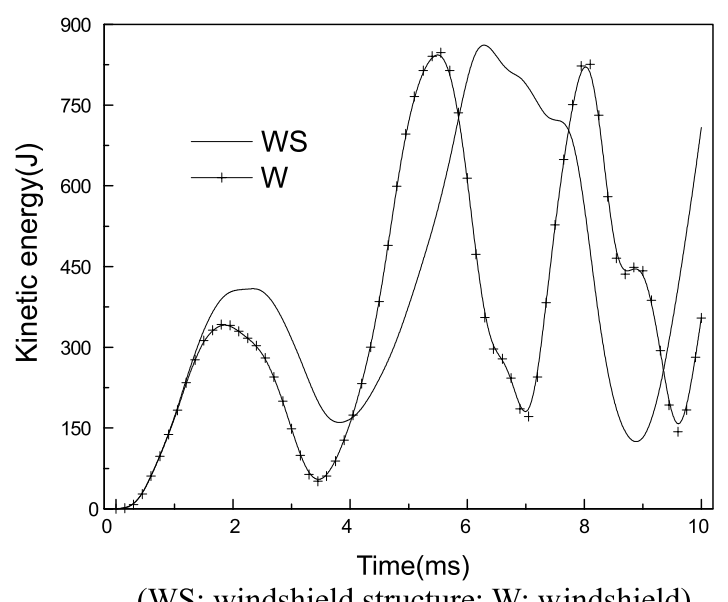

(WS: windshield structure; W: windshield)

Fig. 22. Time history of kinetic energy of windshield.

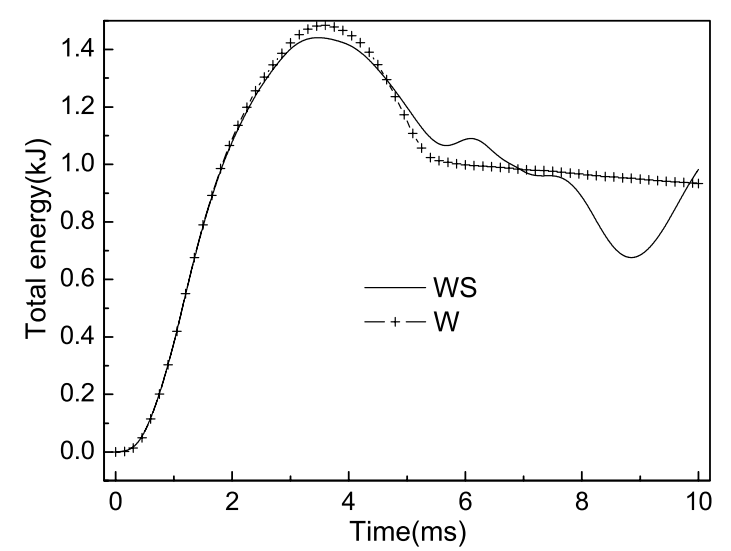

(WS: windshield structure; W: windshield)

Fig. 23. Time history of total energy of windshield. 


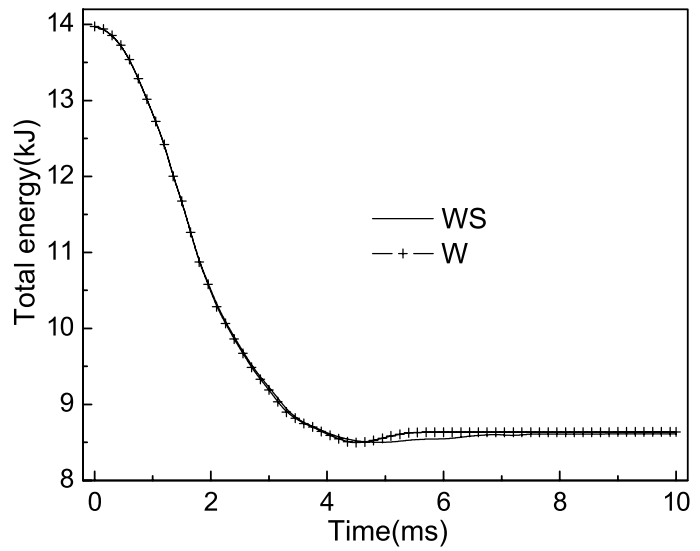

(WS: windshield structure; W: windshield)

Fig. 24. Time history of total energy of bird.

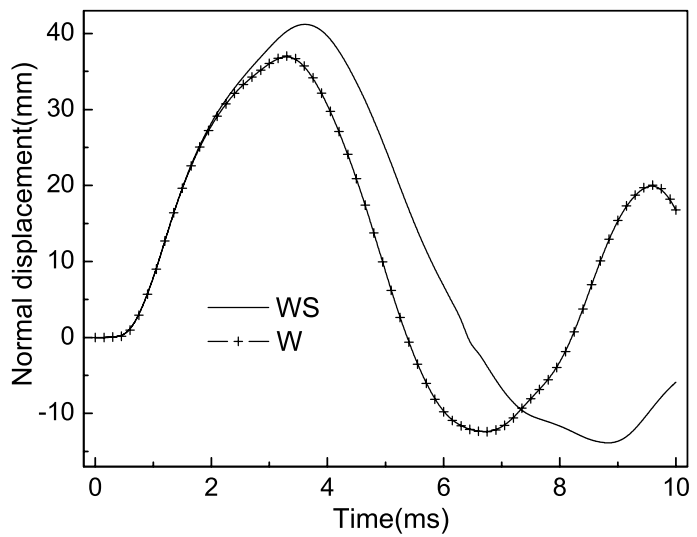

(WS: windshield structure; W: windshield)

Fig. 25. Time history of normal displacement at the center on inner surface of windshield.

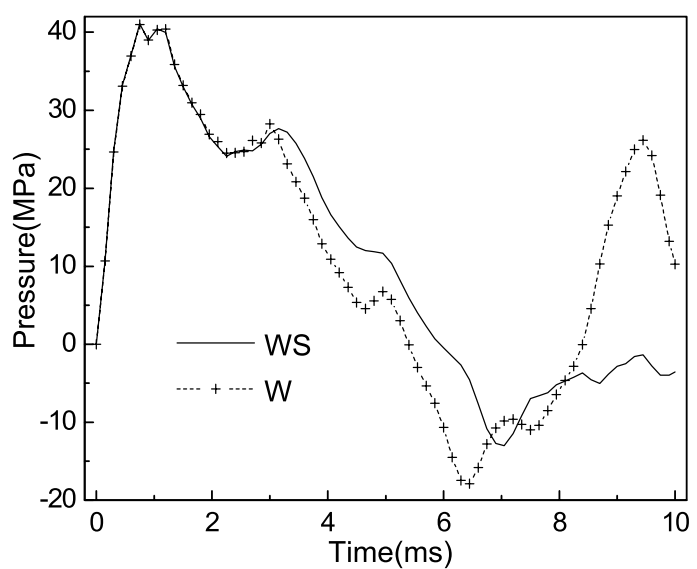

(WS: windshield structure; W: windshield)

Fig. 26. Time history of pressure at initial strike point. 


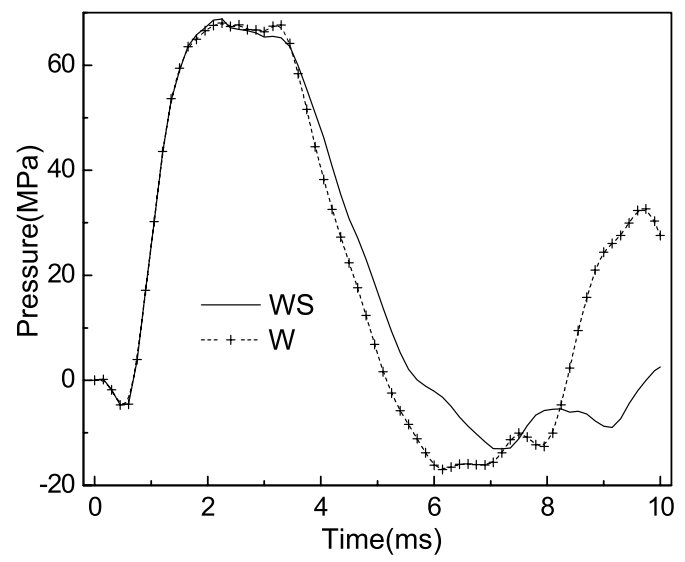

(WS: windshield structure; $\mathrm{W}$ : windshield)

Fig. 27. Time history of pressure at the center on outer surface of windshield.

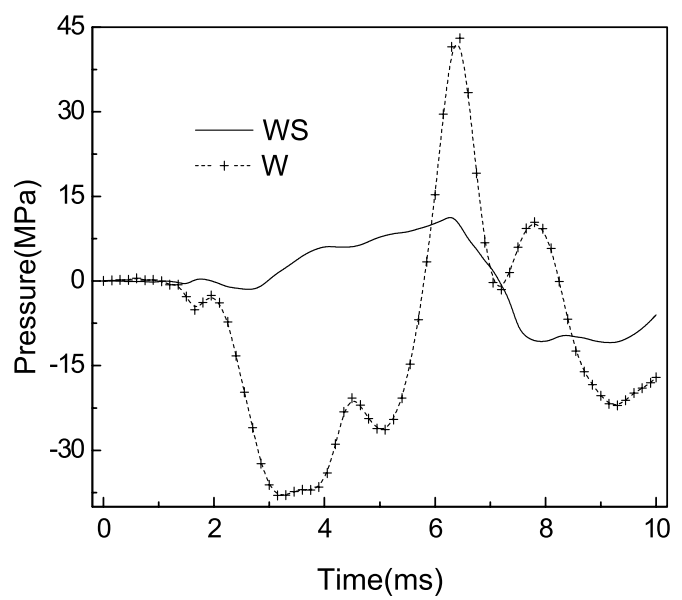

(WS: windshield structure; W: windshield)

Fig. 28. Time history of pressure at vertex of camber line on outer surface of windshield.

total energy of windshield decreases gradually after some time by model of windshield while that by model of windshield structure varies greatly due to energy exchanges between windshield and gasket, gasket and framework and as well as gasket and arc-frame.

(7) Framework, arc-frame and gasket influence greatly on normal displacement at the center on inner surface of windshield structure. The maximal normal displacement by model of windshield structure arrives later and is larger than that by model of windshield.

(8) Framework, arc-frame and gasket influence greatly on pressures at initial strike point, the center and vertex of camber line on outer surface of windshield. The maximal pressures at initial strike point and the center on outer surface are almost the same under the two conditions. While the maximal pressure at vertex of camber line on outer surface by model of windshield is larger than that by model of windshield structure. For each point, variation of pressure by model of windshield is greater than that by model of windshield structure.

\section{Acknowledgements}

This study is supported by National Nature Science Foundation (No:10472094) and Doctoral Foundation (No:N6CJ0001). 


\section{References}

[1] J.Z. Bai, Inverse issue study of bird-impact to aircraft windshield based on neural network method, Xi'an: Northwestern Polytechnical University, 2003.

[2] Z.L. Zhang and W.X. Yao, Research on dynamic analysis of bird impact on aircraft windshield, Acta Aeronoutica et Astronautica Sinica 25(6) (2004), 577-580.

[3] R.E. McCarty, Finite Element Analysis of F-16 Aircraft Canopy Dynamic Response to Bird Impact Loads, AIAA80-0804, 1980.

[4] R.E. McCarty, Finite Element Analysis of A Bird-Resistant Monolithic Stretched Acrylic Canopy Design for The F-16A Aircraft, AIAA81-1640, 1981.

[5] Q.Q. Zhang and Z.Q. Xu, A study of dynamic response for bird impact on arc windshields of aircrafts, Acta Aeronoutica et Astronautica Sinica, 1991, 12(2): B100-B105.

[6] A.J. Wang, X. Qiao and L. Li, Finite element method numerical simulation of bird striking multilayer windshield, Acta Aeronoutica et Astronautica Sinica 19(4) (1998), 446-450.

[7] A.G. Hanssen, Y. Girard and L. Olovsson, A Numerical Model for Bird Strike of Aluminium Foam-based Sandwich Panels, International Journal of Impact Engineering 32(7) (2006), 1127-1144.

[8] Z.H. Xie, W.J. Bian, H.S. Ang et al., The FEM analysis and simulation of bird impact radome with composite sandwich structure, Explosion and Shock Waves 19(3) (1999), 235-241.

[9] S. Audic, M. Berthillier and J. Bonini, Prediction of Bird Impact in Hollow Fan Blades, AIAA2000-3201, 1-7.

[10] A.F. Johnson and M. Holzapfel, Modelling Soft Body Impact on Composite Structures, Composite Structures 61 (2003), 103-113.

[11] M.A. Mccarthy, J.R. Xiao and C.T. Mccarthy, Modelling of Bird Strike on an Aircraft Wing Leading Edge Made from Fibre Metal Laminates-Part 2: Modelling of Impact with SPH Bird Model, Applied Composite Materials 11 (2004), 317-340.

[12] UniGraphics Training Manual, EDS, 2001.

[13] ANSYS User's Manual for Revision 5.7, ANSYS Inc., 2001.

[14] LS-DYNA Theoretical Manual, Livemore Software Technology Corporation, 1998.

[15] X.J. Wang, Z.F. Yue, F.S. Wang et al., Numerical simulation of bird impact dynamic response for windshield, Structure \& Environment Engineering 34(1) (2007), 28-32.

[16] LS-DYNA Keyword User' Manual, Livemore Software Technology Corporation, 2003. 

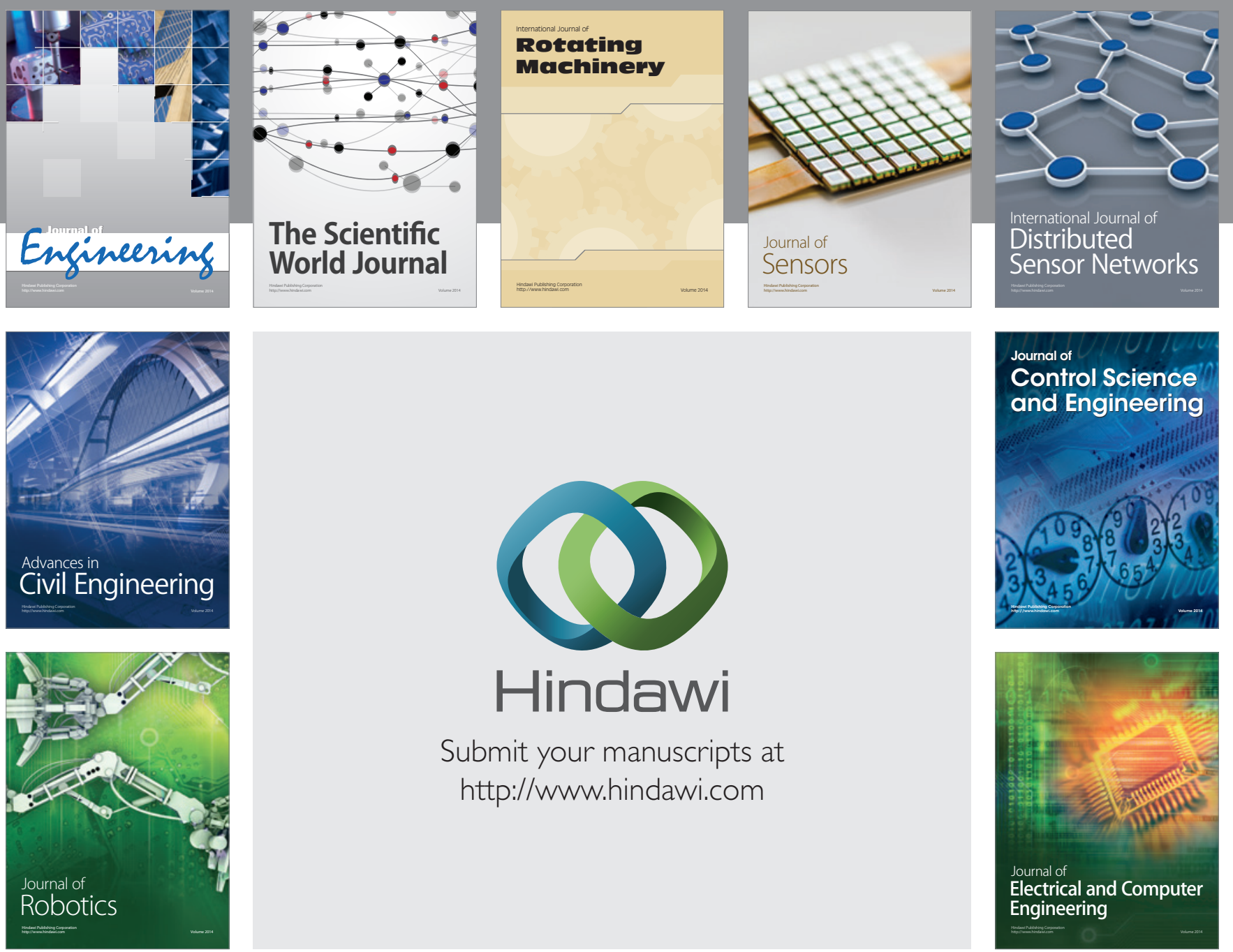

Submit your manuscripts at

http://www.hindawi.com
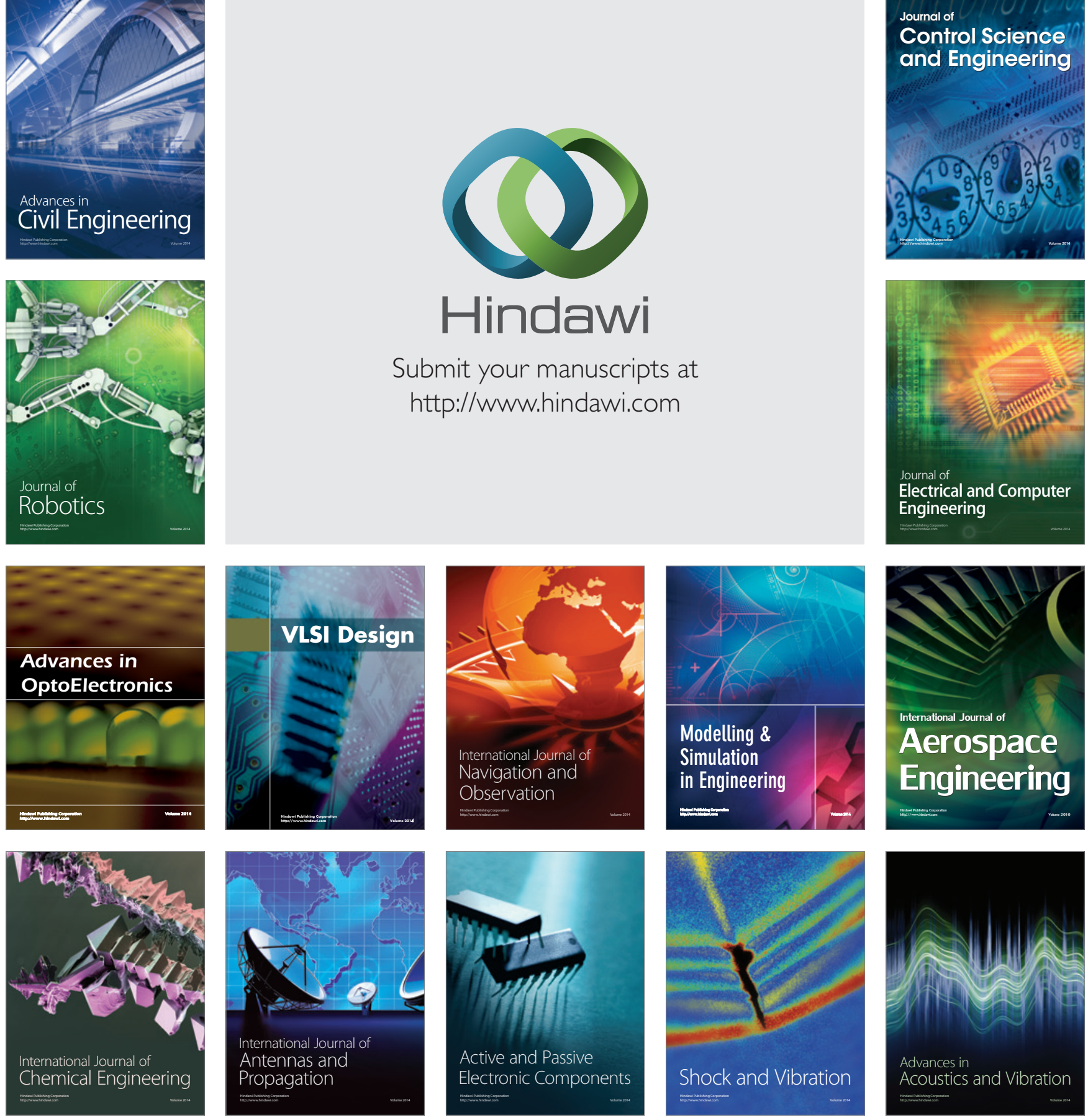